\title{
“EU NÃO GOSTO DO MEU CORPO PORQUE SOU NEGRO E NÃO TENHO PAIS": RESSIGNIFICANDO AS VISÕES SOBRE O CORPO NA ESCOLA A PARTIR DE UMA ABORDAGEM CENTRADA NA EQUIDADE RACIAL
}

\author{
Luiz Gustavo Bonatto Rufino ${ }^{\mathrm{i}}$
}

\begin{abstract}
Resumo: As práticas discursivas engendram estruturas de poder muitas vezes alicerçadas em condutas preconceituosas. A escola, de um lado, coaduna-se com a perspectiva da domesticação dos corpos por meio de práticas racistas e, por outro, possibilita o desenvolvimento de rupturas paradigmáticas. Dessa forma, objetivou-se analisar o processo de intervenção pedagógica relacionado à transformação das visões sobre o corpo a partir de uma abordagem centrada na equidade racial. Por meio de uma pesquisa-ação, desenvolvemos propostas de intervenção pedagógica e registros do processo durante as aulas de Educação Física. Os resultados foram divididos em três categorias: Identidade marcada, abordando o mapeamento do projeto; Identidade em transformação, descrevendo as propostas de intervenção; e, Identidade reconstruída, apresentando os resultados e avaliações do processo. Conclui-se que as intervenções foram potencializadoras de problematização e ressignificação de visões preconceituosas, apontando para a necessidade de fundamentar a educação na perspectiva da equidade racial.
\end{abstract}

Palavras-chave: Corpo; Equidade Racial; Prática Pedagógica; Educação Física; Transformação Social.

\section{"I DON'T LIKE MY BODY BECAUSE I AM BLACK AND I DON'T HAVE PARENTS": RE-MEANING THE VIEWS ON THE BODY IN SCHOOL FROM AN APPROACH FOCUSED ON RACIAL EQUITY}

\begin{abstract}
Discursive practices engender power structures that are often grounded in prejudiced conduct. The school, on the one hand, is consistent with the perspective of the domestication of bodies through racist practices and, on the other, it allows the development of paradigmatic ruptures. Thus, we aimed to analyze the process of pedagogical intervention related to the transformation of views on the body from an approach centered on racial equity. Through an action research, we develop proposals for pedagogical intervention and records of the process during Physical Education classes. The results were divided into three categories: "Identity marked", addressing the mapping of the project; "Identity in transformation", describing the intervention proposals; and, "Reconstructed identity", presenting the results and evaluations of the process. It is concluded that the interventions were potentializing problematization and reframing prejudiced views, pointing to the need to base education from the perspective of racial equity.
\end{abstract}

Keywords: Body; Racial Equity; Pedagogical Practice; Physical Education; Social Transformation. 


\section{Introdução: a construção social da identidade e o desenvolvimento de uma linguagem subalterna nas marcas do corpo}

As sucessivas crises que engendram os modos de agir no mundo em que vivemos denotam a efervescência e a fluidez com que a humanidade tem sido arregimentada na pósmodernidade. Esse tempo de incerteza e permanente transformação tem sido denominado por Bauman (2001) de modernidade líquida, cuja alcunha tem correspondido de forma condizente e relativamente perene com os tempos atuais.

Entre as temáticas abordadas atualmente, o conceito de "identidade" ganha relevo, tornando-se elemento definidor de novos paradigmas. Todavia, atualmente, há um processo de ruptura e transformação acerca das identidades individuais e coletivas, cada vez mais efêmeras e mutáveis. Para Bauman (2005, p. 33), “no admirável mundo novo das oportunidades fugazes e das seguranças frágeis, as identidades ao estilo antigo, rígidas e inegociáveis, simplesmente não funcionam".

Segundo Dubar (2005) e Hall (2006), a identidade é fruto de sucessivos processos de socialização. Trata-se de processos de construção e reconstrução constantes, presentes em todos os momentos da vida, não de maneira linear, mas ocasionados por processos de descontinuidade e rupturas.

Dubar (2005) demonstra que existem dois processos que são, por um lado, relativamente complementares e, por outro, independentes entre si: o processo relacional e o biográfico. A identidade relacional se dá na dimensão objetiva que circunscreve a identidade para o outro, sendo construída por meio da relação entre o sujeito com os demais. A identidade biográfica, por sua vez, comporta a dimensão subjetiva, ou seja, a identidade para si, representando o eixo da construção identitária intersubjetiva da visão sujeito para consigo mesmo.

Dubar (2005) e Hall (2009) consideram que a articulação entre os eixos biográfico e relacional está ancorada em intensos processos de negociação os quais são, via de regra, permeados por trocas entre o que o indivíduo acredita e quer ser, e aquilo que outras pessoas desejam que ele seja. Uma vez que no mundo atual as identidades estão em constante transformação, é possível considerar que há sempre processos de negociação em andamento, provocando um movimento denominado de "identidades em crise" à medida que as visões identitárias do próprio sujeito dificilmente coadunam-se com as representações dos outros (DUBAR, 2009). 


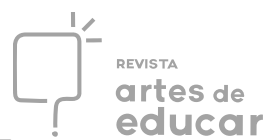

Dentro do processo de construção da identidade, Hall (2009) sublinha o fato dos processos identitários serem construídos dentro dos discursos dos sujeitos, fundamentados em determinados contextos históricos e em instituições específicas. É no interior das práticas discursivas que se marcam as relações de poder que são produto da marcação das diferenças e identidades (HALL, 2009).

Sendo assim, o processo de constituição identitária está arraigado às práticas discursivas que proliferam e naturalizam as narrativas de grupos dominantes. Como salienta Foucault (1979), no ocidente, a partir do século XVIII, tem-se a passagem do paradigma das relações monocráticas de imposição do poder (soberania) para formas de controle mais minuciosas, tais como o poder disciplinar e o controle dos discursos. Desse modo, as práticas discursivas estão fundamentadas por relações de poder por meio de lutas em torno de significação social.

Portanto, a constituição dos processos identitários, arraigados nas relações de poder advindas das práticas discursivas, acabam por incidir nos corpos dos sujeitos de modo determinante. Como salienta Foucault (1979), é por meio do controle dos corpos que o poder se manifesta. Ao naturalizarmos os discursos preconceituosos de dominação da hegemonia de determinados grupos, empreendemos processos de poder que incidem diretamente no corpo dos sujeitos através de discursos e práticas de depreciação. É o caso das narrativas racistas que incidem nos corpos as marcas do preconceito e da discriminação.

Hall (2003) afirma que o conceito de "raça" é uma construção social e política sendo, portanto, uma categoria discursiva em torno da qual se organiza todo um sistema de representação do poder, tanto econômico e social, quanto de exploração e exclusão, isto é, o racismo. Ainda segundo o autor, “o racismo possui uma lógica própria. Tenta justificar as diferenças sociais e culturais que legitimam a exclusão racial em termos de distinções genéticas e biológicas, isto é, na natureza" (HALL, 2003, p. 69).

Não é apenas em ações físicas que o racismo se manifesta, mas também na linguagem, que opera como estruturadora das relações de poder. Assim, como objeto de prática discursiva, o racismo se manifesta também nas instituições e na cultura de forma geral. A escola, como instituição social, alicerça as relações de poder à medida que possibilita uma diversidade de interações sociais e de práticas discursivas que oprimem e manifestam a exclusão e a exploração, possibilitando que o racismo se revele de diferentes maneiras. A naturalização das diferenças e a homogeneização dos discursos faz com que a escola, na atualidade, seja uma instituição crucial para se pensar no paradigma da equidade racial e, 
nesse sentido, contribuir com atitudes que sejam antirracistas e que coíbam e transformem manifestações de racismo (GUIMARÃES, 1999).

Tendo em vista a fundamentação apresentada, podemos compreender que a incorporação dos discursos, isto é, trazer para o corpo as práticas discriminatórias na escola, contribui para o desenvolvimento de atitudes e práticas racistas. Nesse sentido, consideramos que tais práticas discursivas transformam a identidade dos sujeitos e fazem emergir e desenvolver uma "linguagem subalterna nas marcas do corpo" a partir de diferentes processos de subjetivação.

Essa "linguagem subalterna" que cunhamos tem como premissa, seja por meio do eixo biográfico, seja através do eixo relacional da identidade, o enfraquecimento e o arrefecimento da diversidade em prol de atitudes discriminatórias. Como veremos no trabalho, a introjeção de práticas discursivas racistas incide nos corpos dos alunos, sobretudo negros, a partir de uma linguagem subalterna de depreciação de si (ex.: "não gosto de mim porque sou preto") e, com isso, de inapropriação do empoderamento tendo em vista a diversidade social, operando de forma a deslegitimar processos de valorização de si, de autoestima e autocuidado, de valorização da ancestralidade e da história étnica e cultural, de reconhecimento da diversidade como princípio da vida em sociedade e de não reconhecimento da equidade. Lutar para a transformação dessa linguagem subalterna dentro das relações sociais/raciais na escola é condição sine qua non para todo educador comprometido com a equidade racial e com a justiça social.

Assim, o presente estudo objetivou analisar o processo de intervenção pedagógica relacionado à transformação paradigmática das visões sobre o corpo de alunos e alunas do Ensino Fundamental de uma escola pública municipal de periferia do interior do Estado de São Paulo, a partir de uma abordagem centrada na equidade racial.

\section{O contexto de estudo: "uma ponte dividida entre dois mundos" e o racismo incorporado nos discursos discentes}

Atuo em um contexto de periferia no qual prevalece processos de discriminação e diferença social, apresentando inúmeras barreiras em prol da equidade. No entanto, não se tratam apenas de barreiras sociais e históricas, mas também físicas e geográficas.

A cidade (interior do Estado de São Paulo) apresenta uma divisão simbólica a partir de uma ponte que existe no município: de um lado, a região mais próxima ao centro, com escolas Revista Interinstitucional Artes de Educar. Rio de Janeiro, V. 7, N. 1 - pág. 315-332 janeiroabril de 2021: "Pedagogias Vitais: Corpo, Desejo e Educação" DOI: 10.12957/riae.2021.54943 
mais bem equipadas e professores há mais tempo na rede. Do outro, a região mais afastada do centro, periférica e com maiores problemas sociais. Nesse contexto, a discriminação e o descaso com os alunos apresentavam forte relação com o contexto social, contribuindo para a construção de desigualdades e preconceitos. Dentro das problemáticas, o preconceito racial ganhava destaque, sendo de grande presença no interior da escola.

Como professor de Educação Física para os anos iniciais do Ensino Fundamental, o trabalho foi alicerçado em um comprometimento em se entender o corpo e o movimento fundamentado nas práticas corporais e na cultura corporal de movimento. Para isso, os princípios da inclusão de todos nas aulas e da compreensão da diversidade dos alunos e de suas características foram fundamentais e alicerçaram as práticas desenvolvidas.

A fundamentação em propostas, tais como as definidas pelos Parâmetros Curriculares Nacionais (BRASIL, 1998) e pela Base Nacional Comum Curricular (BRASIL, 2017), contribuiu com o desenvolvimento curricular à medida que nos orientou para o trabalho com a diversidade e a equidade social transversalmente aos conteúdos desenvolvidos. O currículo oficial do município também apresentava diversas possibilidades de abordagem pedagógica para as aulas, as quais foram consideradas no desenvolvimento do trabalho docente.

Buscando relacionar o ensino com as competências propostas pela BNCC (BRASIL, 2017), mais especificamente a competência geral 8 (autoconhecimento e autocuidado), realizei algumas atividades de sensibilização corporal com os alunos como forma de contemplar o currículo proposto. Porém, pude perceber que a relação deles com seus corpos era marcada por perspectivas valorativas fundamentadas em formas de poder. Como salienta Foucault (1979):

(...) sobre o corpo se encontra o estigma dos acontecimentos passados do mesmo modo que dele nascem os desejos, os desfalecimentos e os erros; nele também eles se atam e de repente se exprimem, mas nele também eles se desatam, entram em luta, se apagam uns aos outros e continuam seu insuperável conflito. (p. 22)

Todavia, a escola e o processo de escolarização, via de regra, desconsideram o corpo ou o "domestica" e "dociliza", como salienta Foucault (2001). Semelhante a uma prisão, a escola exerce controle nos alunos justamente a partir da disciplinarização dos corpos, exemplificado, entre outras coisas, pelas filas, controle em sala de aula, desconsideração das diversidades corporais e das diferenças entre os alunos, fomento a atitudes discriminatórias, entre outras ações. A partir desse processo de controle, pude perceber as possibilidades de desenvolver novos olhares sobre os corpos que se movimentam. 
Entre outras atividades de mapeamento da realidade, desenvolvemos uma pesquisa com os alunos perguntando sobre a relação deles com seus corpos e se eles gostavam de si. Mais explicitamente, os questionamos sobre o que é o corpo, para que serve o corpo e se eles e elas gostavam ou não do corpo deles e o porquê. Uma quantidade expressiva de alunos apontou não gostar de si mesmo, fato que me instigou a pensar como as crianças têm compreendido e se relacionado com seus corpos.

Do total de 75 alunos que participaram dessa dinâmica inicial, aproximadamente $50 \%$ das respostas demonstraram uma visão depreciativa a respeito de aspectos raciais, como a cor da pele, tipo ou formato do cabelo, cor dos olhos, entre outros. Os outros $50 \%$ de incidência de respostas apresentaram visões positivas sobre si mesmos. Todavia, também estavam alicerçadas em preconceitos. Por exemplo, algumas alunas afirmaram: "eu gosto do meu corpo, porque sou branca, tenho cabelo liso e olhos verdes" (Aluna 12); ou então, "eu sou alta e branca, minha mãe diz que sou linda por isso" (Aluna 44). Nesse sentido, invariavelmente, todas as respostas (positivas ou negativas) culminaram em uma forte incidência de visões preconceituosas ancoradas em práticas sociais/raciais discriminatórias.

Nesse ensejo, passei a desenvolver um projeto para ressignificar as visões de corpo a partir da contextualização das práticas corporais com a perspectiva da equidade racial. Buscou-se fundamentar tais aspectos contextuais que emergiram do mapeamento com a fundamentação legal presente na Lei $n^{\circ}$ 10.639/03 (BRASIL, 2003), que indica a tematização obrigatória de aspectos da história e cultura afro-brasileira, rompendo com visões de preconceito racial.

$\mathrm{O}$ projeto foi alicerçado em uma abordagem voltada à equidade racial, trazendo o corpo para o centro do debate na escola. Como reforça Paulo Freire (1993, p. 8): "estudamos, aprendemos, ensinamos, conhecemos com o nosso corpo inteiro. Com os sentimentos, com as emoções, com os desejos, com os medos, com as dúvidas, com a paixão e também com a razão crítica". Foi dentro desse contexto que o projeto se constituiu e passou a nortear minha prática pedagógica.

\section{Métodos}

Esse estudo apresenta o relato de uma prática de intervenção na escola. Está fundamentado em uma abordagem qualitativa envolvendo observação intensiva e prolongada 


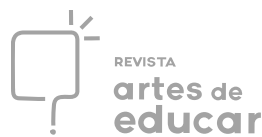

em um ambiente natural, registro detalhado do processo, interpretação e análise de dados e intervenção em uma realidade concreta (THOMAS; NELSON; SILVERMAN, 2007).

Fundamentamos o trabalho sob o vértice das teorias pós-críticas, pós-estruturalistas e nos estudos culturais, mais especificamente nas investigações que buscam descolonizar os currículos escolares e as práticas preconceituosas, discriminatórias e incriminadoras (HALL, 2003). Conforme ressalta Gomes (2012), a descolonização curricular na escola deve estar alicerçada em outro paradigma epistemológico que compreenda a produção de novas formas não eurocêntricas de produção e valorização de saberes. As pesquisas no contexto escolar devem fundamentar-se em posturas que valorizem os saberes cotidianos e as práticas discursivas dos grupos não dominantes. Portanto, é fundamental não realizar propostas de pesquisas sobre os alunos e sim com eles.

Para desenvolver essa postura investigativa optamos pela realização de uma pesquisaação. Diversos autores salientam que dentro das pesquisas sociais com bases empíricas, a pesquisa-ação possibilita não apenas elucidar um problema investigativo, mas também transformar o contexto de atuação a partir de espirais cíclicos de ação e reflexão, sendo, portanto, uma fonte deliberada de transformação da realidade (THIOLLENT, 2008; BARBIER, 2007; FRANCO, 2005).

Sousa Santos (2010) aponta que a pesquisa-ação possibilita a organização comunitária e popular em prol da resolução de problemas específicos de cada realidade. Além disso, contribui com a construção de alternativas, formulando concepções de utilização dos conhecimentos de modo contra-hegemônico (SOUSA SANTOS, 2010). Esse mesmo autor ressalta ainda a importância da produção de conhecimentos a partir de práticas não eurocêntricas, centradas nas "epistemologias do sul" (SOUSA SANTOS; MENESES, 2013).

Na Educação Física, Betti (2009) salienta que a pesquisa-ação possibilita o diálogo permanente entre a prática pedagógica e seus atores, reduzindo o risco do abuso do saber por parte dos pesquisadores. O desenvolvimento de investigações por meio da pesquisa-ação possibilita o tensionamento das relações de poder entre pesquisador e sujeitos pesquisados, minimizando o risco do autoritarismo do discurso científico (BETTI, 2009).

Como salientado, o ponto de partida se referiu ao problema encontrado durante a prática pedagógica: as práticas discursivas racistas por parte dos alunos. Partimos do ponto de vista da construção social identitária e como essa identidade foi afetada por formas de imposição de preconceitos tanto no eixo biográfico quanto no relacional. A problemática que emergiu da prática pedagógica foi o ponto de partida da pesquisa-ação empreendida. 
Participaram dessa intervenção 75 alunos do terceiro ano do ensino fundamental anos iniciais de uma escola pública municipal de periferia do interior do Estado de São Paulo. Esses alunos pertenciam a três diferentes classes de terceiro ano do período vespertino. Os estudantes apresentavam grande diversidade étnico-racial e social, uma vez que a escola atendia alunos da comunidade próxima e também de outros bairros, sendo todos oriundos da periferia da cidade.

A partir do mapeamento inicial foi desenvolvido um conjunto de quinze unidades didáticas (aulas) objetivando o desenvolvimento do projeto. Para isso, articularam-se as vivências das diferentes práticas corporais inseridas no currículo, tais como ginástica artística, atletismo, brincadeiras e jogos, jogos cooperativos, entre outras, com a tematização da questão da equidade racial, tendo em vista a transformação das identidades dos alunos.

Os resultados foram analisados a partir de múltiplas linguagens que se referiram tanto às atividades de estudos e pesquisas, quanto de vivências e desenvolvimento de experiências significativas com as práticas corporais tematizadas. Além disso, os alunos construíram um portfólio de trabalho individual que permitiu a conjugação de todas as produções e registros elaborados por eles, possibilitando a avaliação processual e contínua.

O conjunto de resultados advindo das produções dos alunos, isto é, dos mapeamentos e produções textuais, desenhos, pesquisas, entrevistas ao final do processo, entre outros, foram analisados por meio de diferentes procedimentos ligados à Análise de Conteúdo, partindo-se dos pressupostos estipulados por Bardin (1991). Analisamos a codificação dos textos produzidos e também realizamos análises qualitativas das produções artísticas, tais como os desenhos e as pesquisas desenvolvidas ao longo do processo em cada uma das três etapas do projeto.

\section{Resultados e discussão}

Mediante a análise realizada, emergiram três categorias: Identidade marcada, que buscou apresentar a proposta de mapeamento e iniciação do projeto; Identidade em transformação, a qual procurou demonstrar as propostas de intervenção realizadas e como elas galgaram novas representações sociais; e, Identidade reconstruída, ressaltando os registros e saltos qualitativos encontrados ao longo do processo. 
Identidade marcada: do mapeamento da realidade ao despertar para a problemática

Após o mapeamento inicial que resultou na constatação evidenciada pelas produções dos alunos com relação aos seus corpos, iniciamos um debate acerca de tais constatações. A problematização decorreu com alguns questionamentos a respeito dos motivos que levaram os alunos a apontarem visões valorativas ou depreciativas sobre si mesmo. Percebeu-se que havia um processo de "naturalização" de preconceitos, conforme demonstram Ferreira e Camargo (2001), uma vez que a maior parte das crianças achava "normal" serem consideradas "feias" por elas mesmas, por conta de sua cor, enquanto outras se achavam "bonitas" pelo mesmo motivo.

Questionamos padrões estéticos propostos pelas mídias, pelos pais e até mesmo pela escola. A percepção do preconceito racial foi o primeiro passo, procedido pela problematização em roda. Para isso, utilizamos como inspiração os "ciclos de cultura", propostos por Freire (1982), e, assim, realizamos rodas de conversa fortemente contextualizadas com a realidade dos alunos. Perguntamos quem já havia sofrido preconceitos. Alguns alunos levantaram as mãos e fizeram relatos. Posteriormente, exemplificamos alguns tipos de preconceito racial (depreciação da cor/etnia, realização de piadas ou frases de desvalorização, formas e tratamentos de outras pessoas com relação a si mesmo, entre outros). Nesse momento, muitos alunos perceberam que muitas das frases que eles ouviam eram resultado de processos de preconceito e desvalorização social calcados no racismo. Esse processo de percepção do racismo estrutural da sociedade foi apoiado por alguns recursos, tais como imagens e vídeos.

De posse dos dados do mapeamento e da problematização inicial, passei a estruturar e reorganizar a prática pedagógica, procurando abarcar as vivências das práticas corporais estabelecidas no currículo com a tematização do racismo e da ressignificação das visões de corpo dos alunos. Portanto, a ideia foi "amarrar" as práticas corporais curriculares com a problematização do racismo e suas implicações para a compreensão de equidade racial.

Como forma de tematização inicial, começamos o trabalho com a análise de um breve poema de Eduardo Galeano intitulado Janela sobre o corpo (GALEANO, 2004, p. 138). O poema apresenta a seguinte caracterização: “A Igreja diz: o corpo é uma culpa. A Ciência diz: o corpo é uma máquina. A publicidade diz: o corpo é um negócio. E o corpo diz: eu sou uma festa".

O debate provocado com a análise do poema possibilitou refletirmos sobre como o corpo se apresenta em cada um dos contextos elencados pelo texto. Ao perguntarmos, por Revista Interinstitucional Artes de Educar. Rio de Janeiro, V. 7, N. 1 - pág. 315-332 janeiroabril de 2021: "Pedagogias Vitais: Corpo, Desejo e Educação" DOI: 10.12957/riae.2021.54943 
exemplo, o que seria um corpo em festa, alguns alunos elencaram: "festa é alegria, professor" (aluno 53), ou então, "eu acho que o corpo faz festa pra gente dançar, se divertir" (aluna 32). Essa atividade resultou em uma produção artística dos alunos sobre seus próprios corpos. Ao se desenharem foi possível constatar que muitos alunos passavam por processos de negação de sua cor, raça ou etnia. Assim, ao analisarmos os desenhos em conjunto com os alunos, pudemos perceber como eles se pintavam, como se caracterizavam e como eles se sentiam com relação a essa imagem de si.

Essas reflexões culminaram na análise acerca da importância de se valorizar todas as formas de manifestação cultural e social, começando pela análise do bairro no entorno da escola. Um dos alunos trouxe para o debate que sua família afirmava que algumas atitudes cotidianas, tais como vestimentas utilizadas e formas de se falar eram considerados "coisas de preto" (aluno 4). Aproveitamos esse ensejo para debater o que seria "coisa de preto". Os alunos problematizaram tipos de música, formas de vestimenta e aspectos culturais. A análise possibilitou-nos compreender que havia claras incompreensões e preconceitos escamoteados nos discursos dos alunos, sobretudo com relação à construção social dos conceitos de "negritude" e de "branquitude" (CARONE; BENTO, 2002). O olhar da cultura da branquitude era dominante, de forma que a apropriação de aspectos hegemônicos dessas práticas discursivas ajudou a concretizar a "linguagem subalterna" dos alunos para consigo mesmos.

Como forma de conclusão da etapa inicial, elencamos como eixo norteador para se entender as questões étnicas e raciais a valorização de atletas e personalidades negras. Essa iniciativa foi uma alternativa pedagógica para trazer a representatividade ao centro do debate. Procuramos evitar heroísmos ou o estabelecimento de uma visão meritocrática. Todavia, valorizar atletas negros e sua representação social contribuiu com nosso processo de intervenção.

\section{Identidade em transformação: propostas de intervenção nas aulas e o processo de transformação de si, dos outros e do mundo}

De posse dos dados obtidos do mapeamento e das atividades de diagnóstico, cheguei a alguns eixos de conteúdo que se delinearam como etapas diferentes do processo, apesar de fortemente relacionados entre si, permitindo maior organização da prática pedagógica. $\mathrm{O}$ primeiro eixo foi intitulado $\mathrm{Eu}$, теи corpo e minha história, e objetivou problematizar o Revista Interinstitucional Artes de Educar. Rio de Janeiro, V. 7, N. 1 - pág. 315-332 janeiroabril de 2021: "Pedagogias Vitais: Corpo, Desejo e Educação" DOI: 10.12957/riae.2021.54943 


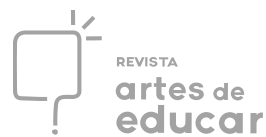

processo de compreensão do corpo e da diversidade racial, propiciando um conjunto de vivências, tendo em vista a exploração de experiências arregimentadas em algumas práticas corporais (atletismo, ginástica, atividades circenses, etc.). Esse processo foi articulado com reflexões sobre os corpos dos alunos na perspectiva da diversidade, trazendo à tona parte de suas histórias de vida e heranças históricas e sociais. Fomentamos assim o eixo biográfico da identidade, seguindo os direcionamentos de Dubar (2005). Procurou-se desenvolver processos de olhar para si e de compreensão das histórias de vida articuladas com as vivências corporais.

O segundo eixo foi denominado $O$ outro e seu corpo, e buscou ampliar as visões de corpo, tendo em vista valorizar as representações e experiências corporais na relação entre os alunos, a exemplo das atividades de delineamento e contorno dos corpos e de algumas atividades em grupo buscando valorizar a relação entre os alunos. Os alunos trocaram experiências e saberes com os colegas na busca pela compreensão da alteridade como elemento orientador do processo de constituição do eixo relacional da identidade (DUBAR, 2005). A diversidade racial e o rompimento com práticas discursivas preconceituosas delinearam o andamento dessa etapa.

O terceiro e último eixo foi caracterizado como $O$ corpo e suas potencialidades $e$ limitações, e explorou as possibilidades apresentadas pelo corpo tanto através do desenvolvimento de vivências que esmiuçassem o trabalho com algumas limitações, objetivando tematizar a inclusão, quanto sobre o tema do Parkour, ampliando os campos de experiência dos alunos. Trouxemos o debate sobre raça e etnia e a desconstrução dos discursos de desvalorização das pessoas negras. Fundamentamos as atividades com debates e reflexões sobre as figuras de negros nos esportes e, ao final, nos propusemos a repensar a igualdade social e a equidade racial no Brasil e no mundo.

Com relação ao primeiro eixo de trabalho, Eu, meu corpo e minha história, procuramos tematizar as práticas corporais presentes no currículo sob a perspectiva da equidade racial e da valorização dos corpos dos alunos. Nesse sentido, a primeira aula abordou o atletismo, mais especificamente as corridas rasas. Por meio das vivências, as crianças buscaram se colocar em diversas situações de desafio permeadas pelas corridas, cada qual dentro de suas limitações. Cada um procurou superar seus próprios limites. O debate transcorreu a partir da contextualização da presença de atletas negros nas corridas. $\mathrm{O}$ nome de Usain Bolt foi muito reconhecido pelos alunos e, por isso, passamos a realizar atividades de pesquisa sobre sua história de vida e superação no esporte. Um dos alunos ressaltou: 
“professor, quando eu crescer quero correr que nem o Bolt e fazer o 'raio' que ele faz assim" (Aluno 38).

Em outra aula abordamos o tema exercício físico e a ginástica e realizamos diferentes movimentos, tais como saltos, posturas e projeções. As experiências de fruição com essas práticas e os desafios individuais realizados possibilitaram grande envolvimento dos alunos. Tematizamos a relação entre alguns e algumas atletas negros/as na ginástica. Alguns alunos reconheceram a brasileira Daiane dos Santos, no qual apresentamos um vídeo contando parte de sua história e trajetória nessa modalidade. Também trouxemos para a discussão o desempenho da atleta norte-americana Simone Biles e suas conquistas nos Jogos Olímpicos do Rio de Janeiro em 2016.

A última aula relacionou-se ao circo, mais especificamente com algumas atividades de malabarismo. Novamente, os alunos foram instigados a pensarem e refletirem sobre os limites e possibilidades de seus corpos durante as vivências. Também analisamos o papel social do circo ao longo do tempo, passando de uma prática de exclusão de pessoas a uma das atividades mais lúdicas e expressivas da atualidade.

Em suma, todas as atividades desenvolvidas nesse eixo procuraram desenvolver formas de análise do eixo biográfico da identidade dos alunos. Para isso, além das vivências, realizamos uma série de dinâmicas de reflexão e produções (textos, desenhos) que contribuíram com o desenvolvimento de novas visões sobre si a partir da consideração da equidade racial como eixo centralizador.

O segundo eixo, $O$ outro e seu corpo, objetivou ampliar as visões de corpo por meio do oferecimento de oportunidades de relações mais efetivas entre os alunos, norteados pelas compreensões de respeito mútuo e diálogo. Inicialmente, os alunos, em duplas, foram direcionados a desenharem seus contornos físicos deitados no chão. Posteriormente, passamos pelos desenhos procurando analisar que, embora sejamos todos iguais em termos de direitos e deveres, cada contorno apresentava suas particularidades. O processo de análise e reflexão, ancorado na dimensão conceitual e atitudinal, foi importante à medida que os alunos exerceram um olhar crítico sobre as ações.

Os alunos foram incitados também a refletirem sobre suas formas físicas, sobre suas cores de pele, características e tipos de cabelo, cor dos olhos, entre outras. Também foram estimulados a desenharem adereços (tatuagens que eles gostariam de ter, brincos, roupas de marca, etc.). Foi um processo fundamental de se colocar no mundo por meio dos corpos. As reflexões foram extremamente potencializadas e retomadas em outras aulas, à medida que 
incitaram novas formas de compreensão, não apenas de suas características físicas, mas de suas ancestralidades e histórias de vida.

Posteriormente, realizamos algumas vivências vinculadas ao tema da "perna de pau", para o qual adaptamos implementos para realizar movimentos com pernas adaptadas de madeira. Através de estratégias como a educação entre pares, os alunos relacionaram-se uns com os outros, mediados pelo professor, tanto vivenciando a ação de andar com as pernas de madeira, quanto auxiliando os colegas nesse processo. Os desafios apresentados nessa aula foram muito motivadores e permitiram desenvolver o aspecto relacional. Tudo foi sintetizado com registros autorais do processo por meio de atividades escritas e de desenhos dos alunos.

Finalmente, o terceiro eixo, denominado $O$ corpo e suas potencialidades e limitações, apresentou a tematização voltada à inclusão, relacionando-se com a experimentação de atividades dirigidas sem visão e com limitações de movimentos. Buscamos problematizar a questão do corpo e suas potencialidades e limitações à medida que os alunos vivenciaram em seus próprios corpos algumas deficiências. Utilizou-se a estratégia da coeducação e da aprendizagem por pares para o desenvolvimento das ações. Ao final, os alunos refletiram sobre as condições de deficiências e importância da inclusão, fundamental para a compreensão de equidade. De modo geral, eles afirmaram terem gostado das experiências proporcionadas pelas aulas, no que correspondeu ao estímulo à criticidade e à alteridade, à medida que as vivências se desenvolveram.

Neste último eixo, vivenciamos uma prática solicitada pelos alunos: o parkour. Exploramos diferentes espaços da escola realizando a transposição de obstáculos. A partir da relação de uns com os outros, eles puderam explorar movimentos e locais e compreender que a Educação pode ser desenvolvida em qualquer espaço da escola, não apenas na sala ou em quadra.

Ainda neste eixo, os alunos realizaram uma produção literária, intitulada $O$ que pode $O$ corpo?, por meio da qual foram estimulados a refletir sobre as vivências e a apresentar visões ressignificadas sobre si e sobre seus saberes e práticas corporais. Os relatos foram democratizados e analisados coletivamente. Esse registro permitiu a troca efetiva de experiências e debates permeados pela ação dialógica e pelo processo de conscientização (FREIRE, 1982).

Além disso, trouxemos a discussão dos atletas e personalidades negras pesquisados pelos alunos e alunas e pelo professor. Atletas como Pelé e Neymar foram os que mais apareceram. Além disso, apresentei alguns atletas internacionais, além daqueles abordados anteriormente, tais como Muhammad Ali, Michael Jordan, Jesse Owens, Tommie Smith, Revista Interinstitucional Artes de Educar. Rio de Janeiro, V. 7, N. 1 - pág. 315-332 janeiroabril de 2021: "Pedagogias Vitais: Corpo, Desejo e Educação" DOI: 10.12957/riae.2021.54943 


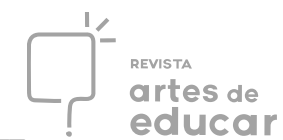

Serena Williams, Teddy Riner etc., e nacionais, a exemplo de João do Pulo, Ademar Ferreira da Silva, Nelson Prudêncio, Aída dos Santos, Formiga, entre outros. As histórias de superação desses e de tantos outros atletas foram um ponto de destaque dos alunos e um conhecimento adquirido e muito propagado por eles ao final do processo.

\section{Identidade reconstruída: os registros, os saltos qualitativos e as dificuldades em se ater a uma sociedade desigual}

Desde o início do processo, focalizou-se nos processos avaliativos, tendo em vista as subjetividades e representações que permeavam as intencionalidades pedagógicas tematizadas. Esse foi um item fundamental, sem o qual eu não conseguiria nem mesmo iniciar os processos de diagnóstico e mapeamento da realidade. Foi através das avaliações que pude tecer compreensões mais aprofundadas sobre o processo como um todo, além de terem me permitido realizar possíveis alterações durante o desenvolvimento das ações.

Para concretizar as intencionalidades pedagógicas foi preciso ampliar e ressignificar as visões de avaliação como aspecto de mensuração ou quantificação. Isso porque, desde o início, foi necessário desenvolver dispositivos que auxiliassem tanto no acompanhamento do processo quanto na obtenção de demonstrações de resultados das ações desenvolvidas.

Foi preciso elaborar estratégias avaliativas que tivessem como parâmetro e característica o fato de serem processuais e contínuas, para um acompanhamento periódico e circunstanciado das práticas. A quantificação e qualificação deveriam ser contextualizadas tendo em vista parâmetros de desempenho e envolvimento dos alunos, não apenas no sentido performático, mas autoral e interpretativo, valorizando aspectos vinculados às dimensões dos conteúdos (conceitual, procedimental e atitudinal).

A criação de um portfólio pedagógico individual foi fundamental para que se pudesse conjugar todas as produções dos alunos de forma processual e contínua. Assim, a cada aula, cada produção de texto, desenho, relato, reflexão, pesquisa ou debate, era juntada com as demais, compondo ao final um inventário de dados para serem analisados e avaliados. Os registros das narrativas de vida, por exemplo, realizados ao longo das primeiras aulas, desencadearam ideias que puderam ser confrontadas ao final, na última produção (o que pode o corpo).

Outro elemento chave da composição dos portfólios foram os desenhos. Não me centrei nas apresentações estéticas dos desenhos. Procurei contextualizar os desenhos naquilo Revista Interinstitucional Artes de Educar. Rio de Janeiro, V. 7, N. 1 - pág. 315-332 janeiroabril de 2021: "Pedagogias Vitais: Corpo, Desejo e Educação" DOI: 10.12957/riae.2021.54943 


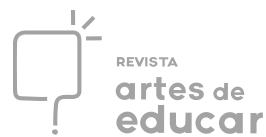

que os alunos procuraram relatar. Além disso, solicitei a eles que me explicassem os desenhos, momento em que novos sentidos e significados apareceram quando eles analisavam suas obras.

O conjunto de estratégias possibilitou o entendimento do trabalho desenvolvido e os registros permitiram a conceituação mais robusta das ações realizadas. As avaliações valorizaram o processo autoral dos alunos e de suas compreensões do trabalho realizado, sem ser quantificável ou aparelhado de forma impositiva ou meramente somativa. As pesquisas realizadas sobre os atletas, personalidades e expoentes da cultura negra também possibilitaram registros importantes.

Em suma, a análise de cada um dos portfólios permitiu compreender que houve relativos saltos qualitativos da forma como os alunos se viam e compreendiam seus corpos e dos demais colegas, para como eles passaram a entender tais questões. $\mathrm{O}$ eixo norteador dessa transformação se deu com a perspectiva da equidade racial, debatida e problematizada criticamente ao longo das aulas.

Após o processo, podemos considerar que a explícita relação entre as práticas corporais e a problematização das visões de corpo e de equidade racial permitiu que o projeto preconizasse uma ampliação de sentidos e significados aos alunos, registrados através das vivências práticas e das atividades e narrativas elaboradas pelas próprias crianças. Ao final, novos sentidos e significados emergiram do processo, demonstrando que a análise dessa temática é de suma importância na atualidade.

\section{Considerações finais: por uma educação do corpo voltada para a equidade racial}

Pensar a educação do corpo e a equidade racial na escola é repensar a própria problemática da escola contemporânea e sua representatividade social. O papel paradoxal da escola faz com que essa instituição caminhe tanto para possibilitar a domesticação dos corpos quanto para provocar a ruptura com antigos paradigmas, rompendo com as relações de poder presentes na sociedade. Tendo em vista essa assertiva, objetivamos analisar o processo de intervenção pedagógica relacionado à transformação paradigmática das visões sobre o corpo de alunos e alunas do Ensino Fundamental de uma escola pública municipal de periferia do interior do Estado de São Paulo, a partir de uma abordagem centrada na equidade racial.

A prática educativa é construída por meio de sucessivos processos de interação humana, de forma que ela é processual e não um produto "pronto e acabado". Tendo em vista Revista Interinstitucional Artes de Educar. Rio de Janeiro, V. 7, N. 1 - pág. 315-332 janeiroabril de 2021: "Pedagogias Vitais: Corpo, Desejo e Educação" DOI: 10.12957/riae.2021.54943 
a problemática do racismo estrutural em nossa sociedade e de todo seu histórico de constituição, não se descontrói paradigmas repentinamente. Trata-se de um processo de reconstrução e de desnaturalização constantes, do qual a instituição escolar não pode se eximir. A equidade racial é eixo fundamental de nossa sociedade, marcadamente desigual. Lutar contra essa desigualdade e desnaturalizar preconceitos cristalizados é condição sine qua non desse processo.

Assim, em que pesem os múltiplos desafios presentes na prática pedagógica, a exemplo das condições de infraestrutura e falta de material na escola, a dificuldade em se desenvolver propostas em contextos de extrema diversidade social e mesmo a representação social que a Educação Física apresenta dentro do contexto escolar de modo mais amplo, os resultados apresentados demonstram que houve um processo de empoderamento e reflexão crítica sobre a equidade racial, que tangenciou as formas de construção e desconstrução de como os alunos compreendiam a si mesmos. Ao final do processo, os alunos romperam com determinados paradigmas cristalizados e incorporados, por meio de contínuos processos de subjetivação de preconceitos. Além disso, puderam compreender o processo de construção de suas identidades e que práticas tidas como naturalizadas devem ser questionadas dentro da escola e que a Educação Física é parte integrante dessa apropriação.

Desse modo, compreendemos que as práticas corporais apresentam possibilidades riquíssimas para se debater a problemática da equidade racial na escola. Apresentar uma visão questionadora e buscar intervir na transformação das vivências cotidianas em experiências significativas é elemento central do papel dos educadores nesse cenário.

Frente à problemática que emergiu, eu não poderia me eximir da corresponsabilidade dessa tematização dada sua centralidade no processo educativo atual. Junto com os alunos, desenvolvemos pesquisas e problematizamos uma questão estrutural na sociedade e que eles, mesmo crianças, vivenciam e trazem incorporados em suas peles e corpos. Uma educação de corpo inteiro se faz à medida que compreendemos a equidade racial como elemento fundante das relações. Que essa temática permaneça como objeto de luta e apropriação na escola, para que o mundo possa se tornar lócus da equidade racial e justiça social.

\section{REFER $\hat{E} N C I A S$}

BARDIN, L. Análise de Conteúdo. Lisboa: LDA, 1991. 
BRASIL. Presidência da República. Lei 10.639 de 9 de janeiro de 2003. Altera a Lei 9.394, de 20 de dezembro de 1996, que estabelece as diretrizes e bases da educação nacional, para incluir no currículo oficial da Rede de Ensino a obrigatoriedade da temática "História e Cultura Afro-Brasileira", e dá outras providências. Disponível em: <http://www.planalto.gov.br/ccivil_03/leis/2003/110.639.htm>. Acesso em: 30/05/2020.

BRASIL. Ministério da Educação e do Desporto. Secretaria de Educação Fundamental. Parâmetros Curriculares Nacionais: Educação Física, 3o e 40 ciclos. Brasília, 1998. v.7.b.

BRASIL, Ministério da Educação. Base Nacional Comum Curricular.Educação é a Base. Terceira Versão - Revista. Brasília: Secretaria da Educação Básica, 2017.

BARBIER, R. A Pesquisa-Ação.Brasília: Liber, 2007.

BAUMAN, Z. Identidade: entrevista a Benedetto Vecchi. Trad. Carlos Alberto Medeiros. Rio de Janeiro: Zahar, 2005.

BAUMAN, Z. Modernidade Líquida. São Paulo: Companhia das Letras, 2001.

BETTI, M. Educação Física escolar: ensino e pesquisa-ação. Ijuí: Unijuí, 2009a.

CARONE, I.; BENTO, M.A.S. (Orgs.). Psicologia Social do Racismo: Estudos sobre branquitude e branqueamento no Brasil. Petrópolis: Vozes, 2002.

DUBAR, C. A crise das identidades: a interpretação de uma mutação. São Paulo: EDUSP, 2009.

DUBAR, C. A socialização: construção das identidades sociais e profissionais. São Paulo: Martins Fontes, 2005.

FERREIRA, R.F.; CAMARGO, A.C. A naturalização do preconceito na formação da identidade do afro-descendente. Eccos Revista Científica, São Paulo, v.3, n.1, p.75-92, 2001.

FRANCO, M.A.S. Pedagogia da pesquisa-ação. Educação e Pesquisa, São Paulo, v.31, n.3, p.483-502, set./ dez. 2005.

FREIRE, P. Pedagogia do Oprimido. 11. ed. Rio de Janeiro: Paz e Terra, 1982.

FREIRE, P. Professora sim, tia não: cartas a quem ousa ensinar. São Paulo: Olho Dágua, 1993.

FOUCAULT, M. Microfísica do poder. Rio de Janeiro: Graal, 1979.

FOUCAULT, M. Vigiar e punir. Petrópolis: Editora Vozes, 2001.

GALEANO, E. As palavras andantes. Porto Alegre: L\&PM, 2004.

GOMES, N.L. Relações étnico-raciais, educação e descolonização dos currículos. Currículo Sem Fronteiras, São Paulo, v.12, n.1, p. 98-109, jan./abr. 2012. 
GUIMARÃES, A.S.A. Racismo e Anti-Racismo no Brasil. São Paulo: Editora 34, 1999.

HALL, S. A identidade cultural na pós-modernidade. 11. ed. Rio de Janeiro: DP\&A, 2006.

HALL, S. Quem precisa de identidade? In: SILVA, T. T. (Org.). Identidade e diferença: $a$ perspectiva dos estudos culturais. 9. ed. Petrópolis: Vozes, 2009.

HALL, S. Da Diáspora: identidades e mediações culturais. Liv Sovik (Org.). Belo Horizonte: Ed. da UFMG, 2003.

SOUSA SANTOS, B. A universidade no século XXI: para uma reforma democrática e emancipatória da Universidade. São Paulo: Cortez, 2010.

SOUSA SANTOS, B.; MENESES, M.P. (Orgs.). Epistemologias do Sul. São Paulo: Cortez, 2013.

THIOLLENT, M. Metodologia da pesquisa-ação. São Paulo: Cortez, 2008.

THOMAS, J. R.; NELSON, J. K.; SILVERMAN, S. J. Métodos de pesquisa em atividade física. Porto Alegre: Artmed, 2007.

\footnotetext{
${ }^{\mathrm{i}}$ Doutor em Ciências da Motricidade, Mestre em Desenvolvimento Humano e Tecnologias e graduado em Educação Física (bacharel e licenciatura) e pedagogia. Prefeitura Municipal de Paulínia - SP e Campinas - SP e Centro Universitário de Jaguariúna - Unifaj. Prefeitura Municipal de Paulínia - SP; Prefeitura Municipal de Campinas - SP; Centro Universitário de Jaguariúna - Unieduk. SP - Brasil. ORCID iD https://orcid.org/0000$\underline{0003-2567-9104}$
} 